\title{
Placenta Praevia: A Study of Risk Factors, Maternal and Fetal Outcome.
}

\author{
Oliver C. Ezechi', Bruno K.E. Kalu', Chikezie A. Nwokoro', Fidelis O. Njokanma', Olabisi M. Loto ${ }^{2}$ \\ and Godwin C.E. Okeke'
}

${ }^{1}$ Havana Specialist Hospital, 115 Akerele Extension, P.O. Box 4631, Surulere, Lagos and ${ }^{2}$ Federal Medical Centre, Owo, Ondo State, Nigeria

\begin{abstract}
Context: With the availability of ultrasound scan, most placenta praevia are detected before symptoms occur. However in most hospitals in Nigeria these facilities are not available and early detection of this condition is still not possible. Majority is diagnosed when symptoms occur. The only useful method of early diagnosis is the use of markers for this condition and early referral to centers were definitive diagnosis can be made.

Objective: To determine the risk factors for placenta praevia in our environment and the associated morbidity and mortality.

Methods: A hybrid, case control and descriptive study of all cases of placenta praevia seen at the Havana Specialist Hospital, Lagos, Nigeria over a period of 3 years (May 2000 April 2003)

Results: The incidence of placenta praevia placenta praevia was $2.6 \%$ with $51.3 \%$ of cases being asymptomatic and $33.3 \%$ presenting as emergency. Some $59.0 \%$ were of minor degree. Majority of patients were delivered at between 34 and 38 weeks. No maternal death occurred, but the perinatal mortality rate was 76.9 per 1000 births. On univariate analysis, multiparity, advanced age, previous placenta praevia, caesarean section and early pregnancy bleeding were significantly associated with placenta praevia. However after multiple logistic regression, only early pregnancy bleeding and previous caesarean section retained their significant association with placenta praevia.

Conclusion: With previous caesarean section and early pregnant bleeding identified as predictors of placenta praevia, early referral to center equipped with scan will not only confirm the diagnosis but will facilitate early and prompt management.
\end{abstract}

Key Word: Placenta Praevia, Antepartum Haemorrhage [Trop J Obstet Gynaecol, 2004;21:131-134]

\section{Introduction}

Antepartum haemorrhage is a grave and potentially life threatening condition which taxes the limits of even the best equipped obstetric unit.. Bleeding from placenta praevia is a leading cause of antepartum haemorrhage. It is also one of the most acute life threatening obstetric emergency. ${ }^{2,3}$ Because of its sudden and unexpected nature, early recognition and prompt management of its associated complications have been advocated. ${ }^{4,5}$

The introduction of ultrasound scan in obstetric practice have improved the diagnostic accuracy and enhanced intervention strategies and outcome.'. While ultrasound scan is readily available in urban centres in Nigeria, converse is the case in most areas of the country. In these areas early diagnosis is even more important for early referral since most hospitals in these areas are ill equipped to handle management problems posed by placenta praevia. Identification of the risk factors associated with this condition before symptoms develop is the alternative strategy towards reduction of morbidity and mortality in these areas. The aim of this study is to determine the incidence, the predisposing/ risk factors, maternal and perinatal effect of placenta praevia in our environment.

\section{Patients and Methods}

This case-control study was conducted at the Havana Specialist Hospital Lagos from May 2000 to April 2003. Havana Specialist Hospital is a multi-disciplinary, 80 bed hospital in the Nigerian cosmopolitan city of
Lagos. It is well staffed with obstetric, neonatal, radiological and anesthetic personnel. Antenatal care is provided under the exclusive supervision of consultant staff. The consultant staff conducts all high-risk deliveries and more than $95 \%$ of normal deliveries.

All patients diagnosed as having placenta praevia either clinically or by Ultrasound scan were recruited into the study. Cases were confirmed at caesarean section. In our hospital all booked patients are routinely scanned at booking and repeats are dictated by clinical development. For unbooked patients they are scanned at presentation in the emergency unit. Transabdominal scan was used routinely but occasionally transvaginal is used. A placenta is confirmed to be praevia if at 34 weeks or above the placenta margin is within $5 \mathrm{~cm}$ of the internal os. ${ }^{6}$

All symptomatic and major placenta praevia were admitted into the ward once the diagnosis is confirmed. Asymptomatic minor placenta praevia were allowed to stay at home after counseling on the natural history of the disease. They were seen as other patients in the antenatal clinic. All symptomatic and major placenta praevia were managed using MacAfee expectant management protocol ${ }^{5}$. The asymptomatic minor placenta praevia was admitted as soon as symptom occurs or if it remains asymptomatic at 37 completed

Correspondence: Dr. Oliver C. Ezechi, P.O. Box 488, Surulere, Lagos. Nigeria.

E-mail: oezechi@yahoo.co.uk

Tel.: 234-1-8033065683, E-fax: 1-928-222-4232 
weeks. All cases were delivered by caesarean section irrespective of the degree. The surgeries were performed under general anaesthesia by consultant staffs. Four units of blood screened for HIV, Hepatitis B and $\mathrm{C}$ were crossed matched for each patient. Four consecutive patients booked for antenatal care or admitted in pregnancy after each case of placenta praevia served as control. They were equally followed up till delivery.

Data were collected for maternal age, parity, gestational age, previous miscarriage, previous caesarean section, uterine scar, pre and postoperative haemoglobin, estimated blood loss, amount of blood transfused, number of bleeding episodes and length of hospital stay, as well as the maternal and fetal outcome. The data collected were entered into the computer using SPSS for windows version 10.0. Frequency and descriptive statistics were computed. Chi square test and t test as appropriate were used to test for significance. P-value less than 0.05 was taken as significant.

\section{Results}

\section{Incidence, Maternal and Perinatal Outcome}

During the period of study; of the 1504 deliveries in the hospital, 39 patients were confirmed to have placenta praevia. The incidence was thus $2.6 \%$.

Table 1 shows the mode of presentation, type of placenta praevia and the gestational age at delivery.

Table 1: Mode of Presentation and Type of Placenta Praevia Among the Study Group

\begin{tabular}{lr}
\hline Parameters & Number of Patients (\%) \\
Mode of Presentation & $19(48.7)$ \\
Asymptomatic & $20(51.3)$ \\
Symptomatic & $13(33.3)$ \\
Early pregnancy bleeding & $13(33.3)$ \\
Emergency & \\
Types & $23(59.0)$ \\
Minor & $12(30.8)$ \\
$I$ & $11(28.2)$ \\
II & $16(41.0)$ \\
Major & $7(17.9)$ \\
$I I I$ & $9(23.1)$ \\
\hline IV &
\end{tabular}

While majority (51.3\%) of cases were asymptomatic an incidental findings at ultrasound scan, the remaining $19(48.7 \%)$ presented either with early pregnancy bleeding (9) or as antepartum haemorrhage (10). Thirteen $(33.3 \%)$ cases presented as emergency. Majority $(59.0 \%)$ of the cases were of minor degree, while the remaining $41.0 \%$ were of major degree. The gestational age at deliveries varied from 34 weeks to 40 weeks, with majority (74.4\%) delivered between 34 and 38 weeks. The remaining $17.9 \%$ and $7.7 \%$ were delivered before 34 weeks or above 38 weeks respectively. The mean gestational age at delivery was $36.6 \pm 3.4$ weeks. The lowest gestational age at delivery was at 26 weeks in a triplet pregnancy complicated by major placenta praevia.

The mean birthweight at delivery was $3.15 \pm 0.6 \mathrm{~kg}$ with majority ( $76.9 \%$ ) weighing $2500 \mathrm{~kg}$ and above and only $9(23.1 \%)$ babies weighed less than $2500 \mathrm{~kg}$. The least weight recorded was $0.65 \mathrm{~kg}$ in the same triplet pregnancy. Seven babies were diagnosed to have birth asphyxia, with majority ( $71.4 \%$ ) being of mild type. Three perinatal deaths occurred; two still birth and one early neonatal death, giving perinatal mortality rate 76.9 per 1000 births. The cause of death in the baby with early neonatal death was respiratory distress syndrome. There were no maternal death recorded, however caesarean hysterectomy was performed in one patient in whom placenta praevia was complicated by placenta pancreata. Thirteen $(33.3 \%)$ patients were transfused with pints of blood ranging from one pint to 9 pints. While majority $(84.6 \%)$ was transfused with 2 to 4 pints of blood, two patients were transfused 5 and 9pints respectively. Postoperative anaemia was the commonest complication $(69.2 \%)$ recorded in these patients. Other complications noted were wound infection (1), urinary tract infection (2), puerperal sepsis (1) and transfusion malaria in 3 .

\section{Risk Factors for Placenta Praevia}

Table 2 shows the sociodemographic characteristics of the women.

Table 2: Socio-Demographic Characteristics of the Women in this Study

\begin{tabular}{lcccc}
\hline Characteristics & $\begin{array}{c}\text { Study } \\
\text { Group }\end{array}$ & $\begin{array}{c}\text { Control } \\
\text { Group }\end{array}$ & $\begin{array}{l}\boldsymbol{X}^{2} \text { OR } \\
\text { t Test }\end{array}$ & P value \\
\hline Mean age (years) & $28.2 \pm 6.0$ & $27.2 \pm 5.1$ & $2.284^{*}$ & 0.04 \\
\multicolumn{5}{c}{} \\
Mean parity & $3.8 \pm 1.5$ & $2.9 \pm 1.1$ & $3.376^{*}$ & 0.002 \\
Socioeconomic class & & & \\
I\&II & $11(28.2)$ & $47(30.1)$ & & \\
III & $21(53.8)$ & $80(51.3)$ & $0.06 €$ & 0.81 \\
IV\&V & $7(18.0)$ & $29(18.6)$ & & \\
Booking status & & & & \\
Booked & $31(79.5)$ & $127(81.4)$ & & \\
Unbooked & $8(20.5)$ & $29(18.6)$ & $0.08 €$ & 0.78 \\
\hline \multicolumn{5}{r}{$*=$ student t test $; €=$ chi square test. }
\end{tabular}

Women with placenta praevia had significantly higher mean maternal age $(p=0.037)$ and parity $(p=0.002)$ than the control, but no significant difference between the two groups when their socioeconomic class $(p=$ $0.81)$ and booking status ( $p=0.78)$ were compared.

Table 3 summarises the result of univariate analysis of obstetric and clinical characteristics of the women in the two groups. The incidences of previous placenta praevia, previous caesarean section, previous abortion, 
multiple pregnancy and early pregnancy bleeding were higher in the women with placenta praevia than in the controls, however only in previous placenta praevia, previous caesarean section and early pregnancy bleeding were the differences between the two groups significant.

Table 3: Obstetric And Clinical Characteristics Of The Women In This Study

\begin{tabular}{lcccc}
\hline Characteristics & $\begin{array}{c}\text { Study } \\
\text { Group }\end{array}$ & $\begin{array}{c}\text { Control } \\
\text { Group }\end{array}$ & X Test & P value \\
\hline $\begin{array}{l}\text { Previous placenta } \\
\text { praevia }\end{array}$ & $7(17.9)$ & $16(10.3)$ & 1.37 & 0.18 \\
$\begin{array}{l}\text { Previous caesarean } \\
\text { section }\end{array}$ & $24(61.5)$ & $43(27.6)$ & 15.97 & 0.000 \\
$\begin{array}{l}\text { Previous abortion } \\
\text { Multiple pregnancy }\end{array}$ & $16(15.4)$ & $9(5.8)$ & 4.06 & 0.04 \\
$\begin{array}{l}\text { Early pregnancy } \\
\text { bleeding }\end{array}$ & $13(33.3)$ & $20(12.8)$ & 9.34 & 0.002 \\
\hline
\end{tabular}

When the characteristics associated with the development of placenta praevia on unvairate analysis were subjected to multiple logistic regression model to control for possible confounding variables, only previous caesarean section (O.R.: 6.2; C.I.: 2.2-18.4) and early pregnancy bleeding (O.R.: 3.6; C.I.: 1.3 -9.7) were associated with placenta praevia.

\section{Discussion}

While several studies have examined risk factors for the development of placenta elsewhere, ${ }^{7,8,9}$ in Nigeria only few retrospective studies have being conducted. ${ }^{4,10} \mathrm{We}$ therefore investigated prospectively the risk factors associated with placenta praevia in our environment. Information thus obtained may help in fashioning strategies to reduce the morbidity and mortality associated with undiagnosed placenta praevia, especially in centres without ultrasound scan. Identifying this risk factors will necessitate prompt and early referral to centres with scan for early diagnosis before symptoms and complication develops.

Previous cacsarean section and early pregnancy bleeding were the most influential risk factors for placenta praevia identified for the development of placenta pracvia in this study. Although multiple pregnancy, previous abortions and previous placenta praevia are well accepted risk factors for placenta praevia, they were not found to be associated with the development of placenta praevia in our patients. The increased incidence of placenta praevia in patients with uterine scar in this study is in agreement with studies of Archibong ${ }^{6}, \mathrm{To}^{7}$ and Taylor. ${ }^{11}$ Taylor $^{11}$ posited that uterine scar in the lower segment may attract a low implantation of the placenta. Pamkay and colleagues ${ }^{12}$ reported a high incidence of placenta praevia among women with early pregnancy bleeding, especially in the second trimester. They argued that the bleeding in these cases is from the low implantation and not because of a threatening pregnancy. ${ }^{12}$

In this report the incidence of placenta praevia of $2.6 \%$ is very high compared to previous studies..$^{16.10 .12,13}$ The high incidence in our centre may be due to high incidence of previous caesarean section as a result of high incidence of cephalopelvic disproportion consequent on the high birth weight in our centre..$^{14}$ Also our centre, being a specialized centre, attracts high risk cases and hence pooling of cases. Important to note is the fewer number of deliveries in our centre compared to other reports. ${ }^{7,8,10,12,13,15.16}$

Although no maternal death occurred in this study, there was a case of placenta percreta necessitating hysterectomy and two women requiring massive blood transfusion. Three perinatal deaths occurred, one early neonatal death at 26 weeks due to respiratory distress syndrome. The two still births were fresh, occurring as a result of massive haemorrhage before admission. In both cases bleeding occurred suddenly and diagnosis of placenta praevia was not made before bleeding occurred. The patients were receiving antenatal care in a government secondary health care centre. Though there was no previous bleeding in both patients, both have had a previous caesarean section with one of the patients having had two previous caesarean sections. Early suspicion and early scan may have prevented this maternal morbidity and perinatal mortality.

Generally, the maternal morbidity in this study was low and compares favourable with the overall maternal outcome in the hospital. This may be attributated to early diagnosis and institution of adequate management; couple with the availability of blood banking services in our centre. Equally important is that all the surgeries were performed by consultant staffs.

This study has demonstrated the high incidence of placenta praevia in our environment with majority been asymptomatic, making a case for routine scan in pregnancy if all cases of placenta praevia must be identified before symptoms occur. In places were finance posses a problem, at least all patients with previous uterine scar and early pregnancy bleeding must have an ultrasound scan done. This study equally demonstrated the associated maternal and fetal morbidity and mortality. With previous caesarean section and early pregnancy bleeding identified as predictors of placenta praevia, early referral to centres equipped with scan and subsequent confirmation of diagnosis will reduce the complications associated with this condition.

\section{References}

1. Khashoggi T, Arab B. Maternal and neonatal outcome 
In major placenta praevia. Ann Saudi Med 1995; 15(4): 1316.

2. Onwudiegwu U, Ezechi OC. Emergency Obstetric admissions: late referrals, misdiagnosis and consequences. Journal of Obstetrics and Gynaecology 2001;21(6):570-575.

3. Onwudiegwu, U, Makinde, ON, Ezechi, OC, Adeyemi, A. Decision caesarean delivery interval in a Nigerian university teaching hospital: implication for maternal morbidity and mortality. Journal of Obstetrics and Gynaecology. 1999; 19(1):30-33.

4. Omu AE, Diejomaoh FME, Omene JAA. The influence of management of placenta praevia on fetal and maternal outcome in a Nigerian community. Singapore JObstet Gynecol 1982; 12: 13-17.

5. MacAfee CHG. Placenta praevia- study of 174 cases. $J$ Obstet Gynecol Br Emp 1945; 52:313-316.

6. Sheriar NK. Ultrasonography of the placenta. In: Kumar P, Rawal MY, Dasgupta S, Rajan R, Malhotra N (eds), Imaging in Obstetrics and Gynaecology. New Delhi, Jaypee brothers medical publishers Ltd. 1998; 94-99.

7. Archibong EI, Ahmed EM. Risk factors, maternal and neonatal outcome in major placenta praevia: a prospective study. Ann Saudi Med 1999; 16(4): 12-16.

8. To WW, Leung WC. Placenta praevia and previous caesarean section. Int. J Gynecol. Obstet 1995; 51:2531
9. Zaki ZM, Bahar AM, Ali ME, Albar HAM, Geraia MA. Risk factors and morbidity in patients with placenta praevia accreta compared to placenta praevia non accreta. Acta Obstet Gynecol Scand 1998; 77:391-394

10. Marinho AO, Jegede DO, Odukoya OA, Ilesanmi AO. Placenta praevia in an unselected Nigeria Obstetric population. WAfr.JMed 1988; 7(1): 19-22

11. Taylor ES. Editorial comments. Obstet Gynecol Surv 1983; 38:96

12. Desai P, Patel P, Ravat C, Desai M. Analysis of obstetric outcome in subjects having history of bleeding per vagina in the first trimester. $J$ Obstet Gynaecol India. 1990;44: 37-40

13. Agboola A. Antepartum Haemorrhage: Incidence, maternal and perinatal outcome. Nig Med J 1971; 1(4): $82-87$

14. Ezechi OC, Nwokoro CA, Kalu BKE, Njokanma OF, Okeke GCE. Caesarean morbidity and mortality in a private hospital in Lagos Nigeria. Trop $J$ Obstet Gynaecol 2002;19(2): 97-100

15. Abu Heija AT, El Jallad F, Ziadeh S. Placenta praevia: effect of age, gravidity, parity and previous caesarean section. Gynecol Obstet Invest 1999; 47: 6-8

16. Hendricks MS Chow YH Bhagvath B, Singh K. Previous caesarean section and abortion as risk factors for developing placenta praevia. Obstet Gynecol Res 1999; 25: $137-142$ 